\title{
DOE-Based Stability Indicating RP-HPLC Method for Determination of Lacidipine in Niosomal Gel in Rat: Pharmacokinetic Determination
}

Mohd Qumbar, Ameeduzzafar, Javed Ali, Syed Sarim Imam, Mohd Fazil and Asgar Ali*

Pharmaceutics Research Lab, Department of Pharmaceutics, Faculty of Pharmacy Jamia Hamdard, New Delhi, India

\begin{abstract}
Lacidipine (LAC) is a calcium channel blocker used in treatment of hypertension. In this study high performance liquid chromatography method (HPLC) is applied to the determination of LAC in rat plasma. The design of experiment used 3- factor 3- level Box Behnken Design for optimization of mobile phase condition. The effluent was monitored by UV detector at $240 \mathrm{~nm}$, at a flow rate of $1.0 \mathrm{~mL} / \mathrm{min}$ using amlodipine as internal standard. A linear calibration curve very well fits our data from $20-1200 \mathrm{ng} / \mathrm{mL}$ with limit of detection (LOD) quantitation (LOQ) 1.490 and 4.848 $\mathrm{ng} \mathrm{mL}-1$ respectively. The method was found to be linear, precise and accurate. Analytes were stable under various conditions (during freeze-thaw, at room temperature, and under deep freeze conditions). The pharmacokinetic study was performed after application of LAC niosomal transgel in rats and results showed enhance bioavailability by 2.57 fold as compared to oral formulation.
\end{abstract}

Keywords: Lacidipine; Box Behnken design; Validation; Niosome; Pharmacokinetics

\section{Introduction}

Lacidipine (LAC) is a calcium channel blocker developed for oral administration and widely used by oral route in treatment of hypertension Figure 1 [1]. It is chemically (E-4-\{2-[3-(1, 1dimethylethoxy)-3-oxo-1-propenyl] phenyl\}-1, 4-dihydro-2, 6-dimethyl-3, 5-pyridine dicarboxylic acid diethyl ester), with molecular formula $\mathrm{C}_{26} \mathrm{H}_{33} \mathrm{NO}_{6}$ and molecular weight of $455.543 \mathrm{~g} / \mathrm{mol}$ [2]. It is also used in the treatment of atherosclerosis, also possesses an antioxidant effect $[3,4]$. It has a high degree of lipophilicity which deposits on the lipid moiety and continuously releases into the binding site during the clean up phase, so it has long duration of action [1]. It undergoes extensive first-pass hepatic metabolism which result to a low oral bioavailability of about $10 \%$. It has long duration of action because of its high degree of lipophilicity. The suggested therapeutic dosage is one $4 \mathrm{mg}$ tablet daily and therapeutic plasma levels are very low (under 5 $\mathrm{ng} / \mathrm{ml}$ at the peak time) [5].

Literature survey revealed that different spectrophotometric method for estimation of lacidipine in various in pharmaceutical dosage form [6-9] like LC-MS/MS in human plasma, [2] UPLC-Tandem MS in human plasma have been reported [5]. Rational practice of design of experiment (DOE) in analytical method development helps to establish a robust mobile phase composition. The utility of design of experiment<smiles>CCOC(=O)C1=C(C)NC(C)=C(C(=O)OCC)C1c1ccccc1/C=C/C(=O)OC(C)(C)C</smiles>

Figure 1: Chemical structure of lacidipine. in LC analytical methods, such as the application of statistical design for the optimization of mobile phase composition for drugs like amoxicillin trihydrate, lenalidomide, voriconazole, risperidone, [1013] and fractional factorial design (FFD) and central composite design (CCD) in the screening and optimization of bioanalytical methods have been extensively investigated [14]. The use of DOE have also been widely explored in metabolite isolation, [15] and impurity profiling using chromatographic procedures [16]. As per prior literature there is no report of an optimized analytical method using experimental design techniques. It was envisaged to develop and validate a simple and fast analytical method by HPLC to quantify LAC in rat plasma by optimization of the mobile phase composition using BBD design. This work describes the validation parameters stated by the ICH guidelines to achieve an analytical method with acceptable characteristics of suitability, reliability and feasibility.

\section{Materials and Method}

\section{Chemicals}

Lacidipine (99.5\% purity) was procured as gift sample from Cadila Health Care (Ahmadabad, India). Acetonitrile HPLC grade, Water for HPLC and Ammonium acetate crystals extra pure were procured from SD fine-chem. Ltd. Mumbai, India. Methanol HPLC grade was procured from Spectrochem Pvt Ltd Mumbai (India). All other chemicals were of AR grade.

\section{Animal}

Albino Wistar rats (6-8 weeks /200-250 g) were approved and

*Corresponding author: Asgar Ali, Dean Faculty of Pharmacy, Jamia Hamdard, New Delhi- 62, India, Tel: +91-9899571726; E-mail: alipharm@gmail.com

Received July 13, 2014; Accepted September 30, 2014; Published October 02, 2014

Citation: Qumbar M, Ameeduzzafar, Ali J, Imam SS, Fazil M, et al. (2014) DOEBased Stability Indicating RP-HPLC Method for Determination of Lacidipine in Niosomal Gel in Rat: Pharmacokinetic Determination. Pharm Anal Acta 5: 314 doi:10.4172/2153-2435.1000314

Copyright: (c) 2014 Qumbar M, et al. This is an open-access article distributed under the terms of the Creative Commons Attribution License, which permits unrestricted use, distribution, and reproduction in any medium, provided the original author and source are credited. 
Citation: Qumbar M, Ameeduzzafar, Ali J, Imam SS, Fazil M, et al. (2014) DOE-Based Stability Indicating RP-HPLC Method for Determination of Lacidipine in Niosomal Gel in Rat: Pharmacokinetic Determination. Pharm Anal Acta 5: 314. doi:10.4172/2153-2435.1000314

Page 2 of 11

provided by Institutional Animal Ethics Committee, and CPSCEA (Committee for the purpose of control and supervision on experiments on animals), Govt of India Central, Animal House of Hamdard University. The rats were housed under controlled environmental conditions (temperature, $25 \pm 5^{\circ} \mathrm{C}$; humidity, $55 \pm 15 \%$; $12 \mathrm{~h} \mathrm{light/dark}$ cycle) and were nourished with pellet diet (Lipton, India) and water ad libitum. The experiments were carried out according to the Guidelines for the Care and Use of Laboratory Animals that was approved by the Committee of Ethics of Animal Experimentation of Jamia Hamdard.

\section{Chromatography condition}

HPLC was performed using a Shimadzu HPLC system (Shimadzu, Model LC-10 ATVP) Japan) equipped with a binary pump and UV detection system (SPD-10A). The chromatographic system operation and recording of data were performed with the use of Class-VP software version 6.21 SP1. Chromatographic separations were achieved on Lichrospher- 100 (Merck) C18 column (average particle size $5 \mu \mathrm{m}$, $250 \mathrm{~mm} \times 4.6 \mathrm{~mm}$ I.D). The mobile phase consisted of acetonitrile and $2-\mathrm{mM}$ ammonium acetate with flow at rate $1.0 \mathrm{ml} / \mathrm{min} .20 \mu \mathrm{L}$ of sample was injected with injection for each run and detection was performed at $240 \mathrm{~nm}$ wavelength with run time of $10.0 \mathrm{~min}$

\section{Preparation of stock, quality control (QC) standard solution}

A primary stock solution of LAC $(100 \mu \mathrm{g} / \mathrm{mL})$ and internal standard $(100 \mu \mathrm{g} / \mathrm{mL})$ were prepared by dissolving in appropriate quantity of methanol and sonicated for $20 \mathrm{~min}$. Standard solutions of LAC at desired concentrations range were prepared by serial dilution of the stock solution with methanol. Calibration standards were prepared by spiking $10 \mu \mathrm{L}$ of the appropriate standard solutions to $100 \mu \mathrm{L}$ of blank rat plasma. The final drug concentrations after sample extraction is 20 $1200 \mathrm{ng} / \mathrm{mL}$. The $20 \mathrm{ng} / \mathrm{mL}$ of internal standard was added in the each sample. The QC samples were prepared independently at four levels $20 \mathrm{ng} / \mathrm{mL}$ (LLQC, lower limit quality control), $40 \mathrm{ng} / \mathrm{mL}$ (LQC, low quality control) $600 \mathrm{ng} / \mathrm{mL}$ (MQC, middle quality control), $1000 \mathrm{ng} /$ $\mathrm{mL}$ (HQC, high quality control) concentrations in the same way as the plasma samples for calibration, and QC samples were stored at $-20^{\circ} \mathrm{C}$ until analysis.

\section{Sample Preparation Protocol}

All the solutions (standards, QC samples and unknown plasma samples) were freshly prepared before carrying out the experiments. The $20 \mu \mathrm{L}$ aliquot of each samples were taken into glass tube containing $100 \mu \mathrm{L}$ blank rat plasma, and $10 \mu \mathrm{L}$ of IS $(20 \mathrm{ng} / \mathrm{mL})$ was added in each sample, and further $500 \mu \mathrm{L}$ of formic acid $(5 \% \mathrm{w} / \mathrm{v})$ was incorporated to mixture and vortexed at $300 \mathrm{rpm}$ for $10 \mathrm{~min}$ ). Finally, the plasma was extracted with $1.5 \mathrm{~mL}$ of ethyl acetate, followed by centrifugation at $6,000 \mathrm{rpm}$ for $5 \mathrm{~min}$ at $20^{\circ} \mathrm{C}$. The supernatant was withdrawn and dried using nitrogen evaporator. The residue was reconstituted with methanol $(500 \mu \mathrm{L})$. THE $10 \mu \mathrm{L}$ of each samples were injected into HPLC system for analysis.

\section{Optimization}

Design of experiment (DOE) was carried out to investigate the behaviour of the response around the nominal values of the factors. The application of DOE has the following advantages: (a) to allow a complete study where all interaction effects are estimated; and (b) to give an accurate description of an experimental region around a centre of interest with validity of interpolation [17-19]. The design shows two to five centre repetitions in order to know the experimental error variance and to test the predictive validity of the model [20]. The Box Behnken Design (BBD) employing a three-factor, three-level using Design-Expert (version 8.0.7.1 software, Stat-Ease Inc., Mineapolis, USA) for optimization of mobile phase. The selected independent variables are acetonitrile (X1), flow rate (X2), and $\mathrm{pH}(\mathrm{X} 3)$, while area (Y1), retention time (Y2), and capacity factor (Y3) was taken as dependent variables (Table 1). A total of 15 experimental runs obtained from Box Behnken design and their observed responses (Table 1), for which the non-linear computer generated quadratic model is defined as;

$\mathrm{Y}=\mathrm{b} 0+\mathrm{b} 1 \mathrm{X} 1+\mathrm{b} 2 \mathrm{X} 2+\mathrm{b} 3 \mathrm{X} 3+\mathrm{b} 12 \mathrm{X} 1 \mathrm{X} 2+\mathrm{b} 13 \mathrm{X} 1 \mathrm{X} 3+\mathrm{b} 23 \mathrm{X} 2 \mathrm{X} 3+$ $\mathrm{b} 11 \mathrm{X} 21+\mathrm{b} 22 \mathrm{X} 22+\mathrm{b} 33 \mathrm{X} 23$

where $\mathrm{Y}$ is the measured response associated with each factor level combination; b0 is constant; b1, b2, b3 are linear coefficients, b12, b13, b23 are interaction coefficients between the three factors, b11, b22, b33 are quadratic coefficients computed from the observed experimental values of $\mathrm{Y}$ from experimental runs; and $\mathrm{X} 1, \mathrm{X} 2$ and $\mathrm{X} 3$ are the coded levels of independent variables. The terms X1 X2 and X12 (i=1, 2 or 3) represent the interaction and quadratic terms, respectively. The responses were statistically evaluated using ANOVA procedure. Further the optimum condition was selected by the numerical optimization

\begin{tabular}{|c|c|c|c|c|c|c|c|c|c|}
\hline \multirow[b]{2}{*}{ Run } & \multirow[b]{2}{*}{$\mathrm{ACN}$} & \multirow{2}{*}{$\begin{array}{c}\text { Flow rate } \\
(\mathrm{ml})\end{array}$} & \multirow[b]{2}{*}{$\mathrm{pH}$} & \multicolumn{2}{|c|}{ Area } & \multicolumn{2}{|c|}{ Retention time } & \multicolumn{2}{|c|}{ Capacity factor } \\
\hline & & & & $\begin{array}{c}\text { Actual value } \\
(\text { Mean } \pm \text { SD) }(n=3)\end{array}$ & $\begin{array}{l}\text { Predicted } \\
\text { value }\end{array}$ & $\begin{array}{c}\text { Actual value } \\
\text { (Mean } \pm \text { SD) }(n=3)\end{array}$ & Predicted value & $\begin{array}{c}\text { Actual value } \\
\text { (Mean } \pm \text { SD) }(n=3)\end{array}$ & Predicted value \\
\hline 1 & 80.00 & 0.80 & 7.00 & $401423 \pm 6248$ & 401603 & $4.03 \pm 0.062$ & 4.01 & $2.36 \pm 0.036$ & 2.37 \\
\hline 2 & 80.00 & 1.00 & 6.00 & $422691 \pm 6023$ & 423410 & $3.68 \pm 0.052$ & 3.69 & $2.05 \pm 0.031$ & 2.06 \\
\hline 3 & 90.00 & 1.00 & 5.00 & $378411 \pm 6157$ & 379013 & $5.13 \pm 0.065$ & 5.11 & $3.24 \pm 0.051$ & 3.24 \\
\hline 4 & 90.00 & 1.20 & 6.00 & $349467 \pm 4529$ & 349119 & $4.48 \pm 0.061$ & 4.50 & $2.73 \pm 0.044$ & 2.74 \\
\hline 5 & 90.00 & 0.80 & 6.00 & $359129 \pm 5488$ & 359312 & $4.62 \pm 0.064$ & 4.63 & $2.84 \pm 0.041$ & 2.85 \\
\hline 6 & 90.00 & 1.00 & 7.00 & $427143 \pm 6759$ & 426804 & $4.52 \pm 0.066$ & 4.51 & $2.78 \pm 0.043$ & 2.79 \\
\hline 7 & 70.00 & 0.80 & 6.00 & $285321 \pm 4581$ & 285711 & $3.74 \pm 0.051$ & 3.72 & $2.11 \pm 0.029$ & 2.12 \\
\hline 8 & 80.00 & 1.00 & 6.00 & $422658 \pm 6589$ & 423407 & $3.68 \pm 0.058$ & 3.69 & $2.06 \pm 0.029$ & 2.06 \\
\hline 9 & 70.00 & 1.00 & 5.00 & $378854 \pm 6772$ & 379209 & $3.43 \pm 0.054$ & 3.44 & $1.84 \pm 0.025$ & 1.85 \\
\hline 10 & 80.00 & 0.80 & 5.00 & $412894 \pm 7025$ & 412217 & $4.09 \pm 0.056$ & 4.07 & $2.41 \pm 0.037$ & 2.43 \\
\hline 11 & 80.00 & 1.00 & 6.00 & $424759 \pm 6855$ & 423434 & $3.69 \pm 0.055$ & 3.68 & $2.07 \pm 0.027$ & 2.06 \\
\hline 12 & 80.00 & 1.20 & 7.00 & $401267 \pm 5496$ & 402006 & $3.72 \pm 0.061$ & 3.71 & $2.15 \pm 0.031$ & 2.15 \\
\hline 13 & 70.00 & 1.00 & 7.00 & $305821 \pm 3544$ & 305308 & $4.03 \pm 0.049$ & 4.01 & $2.35 \pm 0.033$ & 2.36 \\
\hline 14 & 80.00 & 1.20 & 5.00 & $417741 \pm 6554$ & 417510 & $3.69 \pm 0.052$ & 3.68 & $2.07 \pm 0.027$ & 2.08 \\
\hline 15 & 70.00 & 1.20 & 6.00 & $301623 \pm 3624$ & 301505 & $3.17 \pm 0.039$ & 3.18 & $1.65 \pm 0.021$ & 1.66 \\
\hline
\end{tabular}

Table1: Observed values of responses for Box-Behnken design (Design Expert 8.0.7.1) 
Citation: Qumbar M, Ameeduzzafar, Ali J, Imam SS, Fazil M, et al. (2014) DOE-Based Stability Indicating RP-HPLC Method for Determination of Lacidipine in Niosomal Gel in Rat: Pharmacokinetic Determination. Pharm Anal Acta 5: 314. doi:10.4172/2153-2435.1000314

procedure using the desirability function.

\section{Validation method}

The validation of an analytical method confirms the characteristics of the method to satisfy the requirements of the application domain [21]. The method was validated following parameters like for specificity, repeatability, linearity, precision, robustness, recovery and stability as per ICH Guidelines.

\section{Specificity}

Specificity is the ability to assess the analyte in presence of components which may be expected to be present. The selectivity of the method was evaluated by comparing the chromatograms of six different batches of blank rat plasma with the corresponding spiked plasma (LLOQ samples), so as to ensure no interfering peak of LAC and I.S. from endogenous plasma.

\section{Linearity and sensitivity}

The concentrations of $20,40,100,200,400,600,800,1000$, and 1200 $\mathrm{ng} / \mathrm{mL}$ were used to assess linearity. The calibration standards of LAC in plasma sample were prepared by liquid-liquid extraction method. The calibration curve was plotted between concentrations vs. peak area ratio of drug to IS of the nominal concentration. Least-squares linear regression method was used to determine the slope, intercept and correlation coefficient. The limit of detection and quantification (LOD \& LOQ) is defined as the concentration that produced a signalto-noise $(\mathrm{S} / \mathrm{N})$ ratio of at 3:1 and 10:1. The LOD \& LOQ of sample were determined by following formula.

Where SD is Standard Deviation

\section{Precision and accuracy}

The precision and accuracy was determined by analyzing QC samples at 4 levels (LLQC, LQC, MQC, and HQC concentrations). The QC samples were analysed six times a day to evaluate intra-day precision and accuracy. The same procedure was performed once a day for three consecutive days for inter-day precision and accuracy. The accuracy and precision were calculated using the formula and was expressed as relative standard deviation (RSD).

\section{Extraction recovery and matrix effect}

The extraction recovery of LAC was evaluated at four QC concentrations: 20, 40, 600, and $1000 \mathrm{ng} / \mathrm{mL}$. Extraction recovery was determined by comparing the peak areas obtained from blank plasma spiked with analytes before the extraction with those from samples to which analyte were added after the extraction $[22,23]$. Matrix effect was also determined at LLQC, LQC, MQC and HQC concentrations, viz. $20,40,600$, and $1000 \mathrm{ng} / \mathrm{mL}$, and assayed to compare the peak areas of blank plasma extracts spiked with analyte with those of the standard solutions dried and reconstituted with mobile phase.

\section{-Robustness}

Robustness of the method was determined by making slight changes in the chromatographic conditions, such as change in mobile phase, flow rate and column temperature. The method was done at 4 levels of different spiked plasma QC samples (LLQC, LQC, MQC, and HQC concentrations).

\section{Stability assessment}

The stability study was performed to evaluate the stability of the analyte in plasma under the following conditions: short-term stability at room temperature for $24 \mathrm{~h}$; long-term stability at $-80^{\circ} \mathrm{C}$ for 30 days, freeze thaw (three cycle at $20-25^{\circ} \mathrm{C}$ ) cycles for three consecutive days and post preparative stability of the processed samples kept under normal conditions $\left(25 \pm 2^{\circ} \mathrm{C}\right)$ for $24 \mathrm{~h}$. All stability testing in rat plasma were performed at the LQC and HQC concentrations $(n=6)$. Stability was determined by statistical comparison of the calculated concentrations.

\section{Forced degradation studies}

The forced degradation studies were conducted on sample using acid, alkaline, oxidative, thermal, photolytic, and UV degradations. The sample was exposed to these conditions and main peak was studied for the peak purity, thus indicating that the method effectively separated the degradation products from the pure active ingredient [24]. A stock solution containing $10 \mathrm{mg}$ lacidipine in $50 \mathrm{~mL}$ methanol was prepared. This solution was used for forced degradation.

\section{Preparation of acid and base induced sample}

To the volume of $10 \mathrm{~mL}$ of methanolic stock solution, $10 \mathrm{~mL}$ of $1 \mathrm{~N}$ $\mathrm{HCl}$ and $10 \mathrm{~mL}$ of $1 \mathrm{~N} \mathrm{NaOH}$ were added separately. These mixtures were refluxed for $6 \mathrm{~h}$ at $90^{\circ} \mathrm{C}$. The forced degradation in acidic and basic media was performed in the dark in order to exclude the possible degradative effect of light. The sample was diluted with methanol to obtained desired concentration $(100 \mathrm{ng} / \mathrm{mL})$. Finally sample was filtered through $0.2 \mu \mathrm{m}$ filter and then injected into the HPLC system.

\section{Preparation of hydrogen peroxide-induced sample}

To the volume of $10 \mathrm{~mL}$ of methanolic sample was added in $10 \mathrm{~mL}$ of hydrogen peroxide $(30 \%, \mathrm{v} / \mathrm{v})$ was added. The solution was refluxed in boiling water bath for $6 \mathrm{~h}$ at $90^{\circ} \mathrm{C}$ to remove completely the excess of hydrogen peroxide. The sample was diluted with methanol to obtained desired concentration $(100 \mathrm{ng} / \mathrm{mL})$ and sonicated for $5 \mathrm{~min}$. The sample filtered through $0.2 \mu \mathrm{m}$ filter and then injected into the HPLC system. The obtained chromatogram was analyzed.

\section{Photochemical degradation induced sample}

The photochemical stability of the drug sample was performed by exposing to direct sunlight and ultraviolet for $24 \mathrm{~h}$. The sample was diluted with methanol to obtained desired concentration $(100 \mathrm{ng} / \mathrm{mL})$ sonicated for $5 \mathrm{~min}$. Finally the sample filtered through $0.2 \mu \mathrm{m}$ filter and then injected into the HPLC system.

\section{Preparation of niosome gel}

LAC niosomes were prepared by film deposition technique using span60 as non-ionic surfactant [25]. Appropriate amount of LAC, cholesterol and span 60 was dissolved in methanol/chloroform mixture (2:1), placed in a round bottom flask. The organic solvent was removed under vacuum by a rotary evaporator (Model-HS-2005V-N, Hahnshin Scientific Co. Korea) at $60^{\circ} \mathrm{C}$ to form a thin film on the wall of the flask. The flask was kept in a desiccator under vacuum for 4-8 h to ensure total removal of trace solvents. The film was hydrated with 10 $\mathrm{ml}$ of phosphate buffer and dispersion was left to equilibrate at room temperature to ensure complete annealing and drugs distribution between the lipid bilayer and the aqueous phase. The formulation was converted into gel using carbopol $934(1 \% \mathrm{w} / \mathrm{w})$. Niosomal dispersion was added to hydrated carbopol solution with stirring. Other ingredients, such as $15 \% \mathrm{w} / \mathrm{v}$ polyethylene glycol-400 (PEG-400) and triethanolamine $(0.5 \% \mathrm{w} / \mathrm{v})$, were added to obtain homogeneous dispersion of gel, and this niosomal gel formulation was used in vivo pharmacokinetic studies. 
Citation: Qumbar M, Ameeduzzafar, Ali J, Imam SS, Fazil M, et al. (2014) DOE-Based Stability Indicating RP-HPLC Method for Determination of Lacidipine in Niosomal Gel in Rat: Pharmacokinetic Determination. Pharm Anal Acta 5: 314. doi:10.4172/2153-2435.1000314

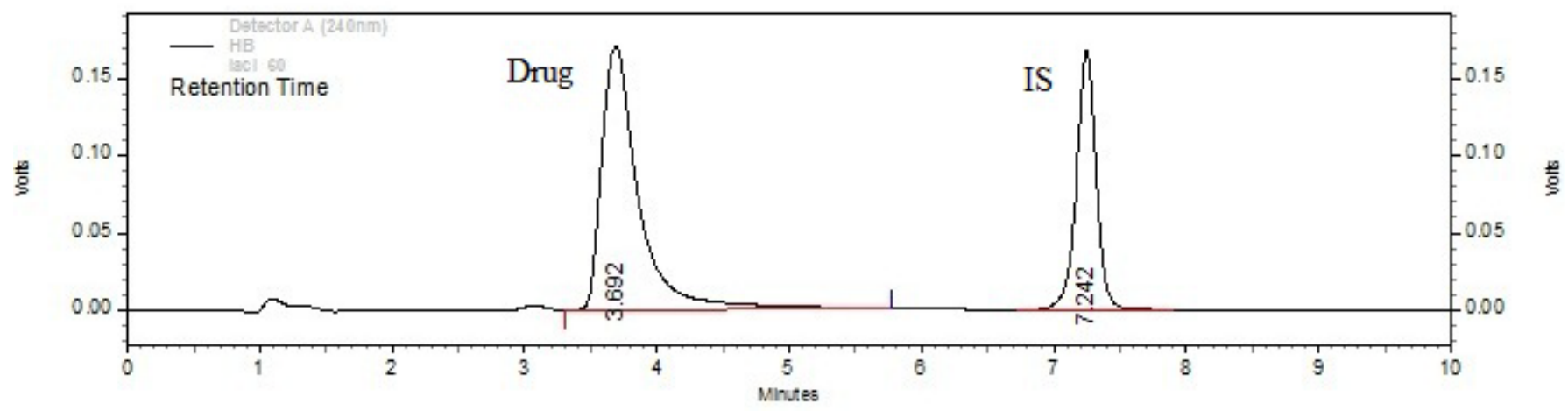

Figure 2: Typical HLPC chromatogram of lacidipine and internal standard (IS).

\begin{tabular}{|c|c|c|c|c|c|c|}
\hline Model & $\mathbf{R}^{2}$ & Adjusted $\mathbf{R}^{2}$ & Predicted $\mathbf{R}^{2}$ & SD & $\% \mathrm{CV}$ & Remark \\
\hline $\begin{array}{c}\text { Response }\left(Y_{1}\right) \\
\text { Linear } \\
2 F I \\
\text { Quadratic }\end{array}$ & $\begin{array}{l}0.2318 \\
0.3485 \\
0.9998\end{array}$ & $\begin{array}{c}0.0223 \\
-0.1401 \\
0.9996\end{array}$ & $\begin{array}{c}-0.4708 \\
-1.7366 \\
0.9987\end{array}$ & $\begin{array}{c}48194.01 \\
52043.04 \\
1010.61\end{array}$ & $\begin{array}{c}- \\
- \\
0.027\end{array}$ & $\begin{array}{c}- \\
\text { - } \\
\text { Suggested }\end{array}$ \\
\hline $\begin{array}{c}\text { Response }\left(Y_{2}\right) \\
\text { Linear } \\
2 F I \\
\text { Quadratic }\end{array}$ & $\begin{array}{c}0.7119 \\
0.8232 \\
1.000\end{array}$ & $\begin{array}{l}0.6333 \\
0.6906 \\
0.9999\end{array}$ & $\begin{array}{l}0.4535 \\
0.3548 \\
0.9997\end{array}$ & $\begin{array}{c}0.31 \\
0.29 \\
4.830 \mathrm{E}-003\end{array}$ & $\begin{array}{c}- \\
- \\
0.12\end{array}$ & $\begin{array}{c}- \\
\text { - } \\
\text { Suggested }\end{array}$ \\
\hline $\begin{array}{c}\text { Response }\left(Y_{3}\right) \\
\text { Linear } \\
2 \mathrm{FI} \\
\text { Quadratic }\end{array}$ & $\begin{array}{l}0.7485 \\
0.8255 \\
0.9999\end{array}$ & $\begin{array}{l}0.6418 \\
0.6946 \\
0.9996\end{array}$ & $\begin{array}{l}0.4734 \\
0.3914 \\
0.9989\end{array}$ & $\begin{array}{c}0.25 \\
0.23 \\
8.367 E-003\end{array}$ & $\begin{array}{c}- \\
\overline{0} \\
0.36\end{array}$ & $\begin{array}{c}- \\
\text { - } \\
\text { Suggested }\end{array}$ \\
\hline $\begin{array}{l}Y_{1}(\text { Area })=+423400+ \\
16817.08^{*} \mathrm{C}^{2}- \\
Y_{2}(\mathrm{Rt})=+3.68+0.55^{*} \mathrm{~A} \\
Y_{3}(\text { Capacity factor })=\end{array}$ & $\begin{array}{l}A+1416 \\
E 003^{*} \\
A-0.14^{*}\end{array}$ & $\begin{array}{l}530.75^{*} \mathrm{C} \\
0.30^{*} A^{*} \mathrm{C}+ \\
-002{ }^{*} \mathrm{C}+0 .\end{array}$ & \multicolumn{4}{|c|}{$\begin{array}{l}{ }^{*} B^{*} C+0.36^{*} A^{2} 0.038^{*} B^{2}+0.24^{*} C^{2}-00{ }^{*} A^{*} B+30441.25^{*} A^{*}-1250.75^{*} B^{*} C-67629.17^{*} A^{2} 31855.17^{*} B^{2}+ \\
{ }^{*} B-0.24^{*} A^{*} C+0.033^{*} B^{*} C+0.29^{*} A^{2}-0.016^{*} B^{2}+0.20^{*} C^{2}--- \text { equation } 3\end{array}$} \\
\hline
\end{tabular}

Table 2: Summary of results of regression analysis for responses $Y_{1}, Y_{2}$ and $Y_{3}$.

\section{Characterisation of niosome and niosomal gel}

Niosome were characterised for size, size distribution, polydispersity index, and entrapment efficiency. Zetasizer (3000-HS, Malvern Instruments, UK) was used for measurement of size, size distribution, zeta potential and polydispersity index. Entrapment efficiency was measured by ultracentrifugation method [25]. The viscosity of the niosomal gel was measured using rheometer. The flux was measured by the ex vivo permeation study by using Franz diffusion cell on rat abdominal skin.

\section{Pharmacokinetic study}

A total of 12 Albino Wistar rats were randomly divided into two groups of 6 animals each (Group1 for oral suspension and group 2 for transdermal niosomal gel of LAC). The hairs on the abdominal skin of group 2 was removed and cleaned. The calculated dose of oral suspension was administered using oral feeding sonde and niosomal transgel was applied on rat skin. The blood sample was collected at 0 , $1,2,4,8,12,16,24$, and $48 \mathrm{~h}$ in tube containing of disodium EDTA as an anticoagulant. All blood samples were centrifuged at $4000 \mathrm{rpm}$ for $10 \mathrm{~min}$, and the plasma samples were collected and stored at $-4^{\circ} \mathrm{C}$ until analysis. The maximum plasma concentration $\left(\mathrm{C}_{\max }\right)$ and the time to reach maximum concentration $\left(\mathrm{T}_{\max }\right)$ were directly determined from the plasma concentration versus time curves. The area under the curve from 0 to $\mathrm{t}(\mathrm{AUC} 0-48)$, from 0 to $\infty(\mathrm{AUC} 0-\infty)$ and area under first moment curve from $0-48$ (AUMC0-48) were calculated. Whereas, the elimination rate constant $(\mathrm{Ke})$ was calculated as the slope of the terminal portion of the log (plasma concentration) versus time curve. The elimination half-life ( $\mathrm{t} 1 / 2)$ was calculated using the PK relationship $(\mathrm{t} 1 / 2=\log 2 / \mathrm{Ke})$.

\section{Result and Discussion}

\section{Method development}

The HPLC method was developed and optimized using DOE approach taking various mobile phase combinations. There are various mobile phase compositions was used but peak did not separate properly. Finally the optimised chromatographic separation of LAC was achieved by using acetonitrile: $5 \mathrm{mM}$ ammonium acetate, which gave good chromatographic separation as compared to other solvent system as described earlier (Figure 2). Then the final optimization of this solvent system was done by Box-Behnken statistical design for accurate and précised chromatographic separation.

\section{Optimization}

To study the simultaneous variations of the factors on the considered responses, a multivariate approach BBD through DOE was applied. A three factor three level BBD consisting of fifteen experimental runs including three centres point was used. The chromatographic conditions ranges selected were acetonitrile (70-90\%), flow rate (0.8$1.2 \mathrm{ml} / \mathrm{min}$ ) and $\mathrm{pH}(5-7)$ respectively for area (Y1), retention time (Y2) and capacity factor (Y3). The experimental design of the selected variables with their predicted and actual responses was reported in Table 1. All the responses observed for fifteen runs were fitted to various 
Citation: Qumbar M, Ameeduzzafar, Ali J, Imam SS, Fazil M, et al. (2014) DOE-Based Stability Indicating RP-HPLC Method for Determination of Lacidipine in Niosomal Gel in Rat: Pharmacokinetic Determination. Pharm Anal Acta 5: 314. doi:10.4172/2153-2435.1000314

Page 5 of 11

\begin{tabular}{|c|c|c|c|}
\hline Result of the analysis of variance & Area & Rt (min) & Capacity factor \\
\hline $\begin{array}{c}\text { Regression } \\
\text { Sum of squares } \\
\text { degrees of freedom (df) } \\
\text { Mean squares } \\
\text { F-value } \\
\text { P }\end{array}$ & $\begin{array}{c}3.325 E+010 \\
9 \\
3.695 E+009 \\
3617.72 \\
<0.0001\end{array}$ & $\begin{array}{c}3.72 \\
9 \\
0.41 \\
17727.06 \\
<0.0001\end{array}$ & $\begin{array}{c}2.52 \\
9 \\
0.28 \\
4006.37 \\
<0.0001\end{array}$ \\
\hline $\begin{array}{l}\text { Lack of Fit Tests } \\
\text { Sum of squares } \\
\text { degrees of freedom (df) } \\
\text { Mean squares } \\
\text { F-value } \\
\text { P }\end{array}$ & $\begin{array}{c}2.209 E+006 \\
3 \\
7.365 E+005 \\
0.51 \\
0.7154\end{array}$ & $\begin{array}{c}5.000 E-005 \\
3 \\
1.667 E-005 \\
0.50 \\
0.7194\end{array}$ & $\begin{array}{c}1.500 \mathrm{E}-004 \\
3 \\
5.000 \mathrm{E}-005 \\
0.50 \\
0.7194\end{array}$ \\
\hline $\begin{array}{c}\text { Residual } \\
\text { Sum of squares } \\
\text { degrees of freedom (df) } \\
\text { Mean squares }\end{array}$ & $\begin{array}{c}5.107 E+006 \\
5 \\
1.021 E+006\end{array}$ & $\begin{array}{c}1.167 E-004 \\
5 \\
2.333 E-005\end{array}$ & $\begin{array}{l}3.500 \mathrm{E}-004 \\
5 \\
7.000 \mathrm{E}-005\end{array}$ \\
\hline
\end{tabular}

Table 3: Analysis of variance of calculated model for responses (Design Expert 8.0.7.1).
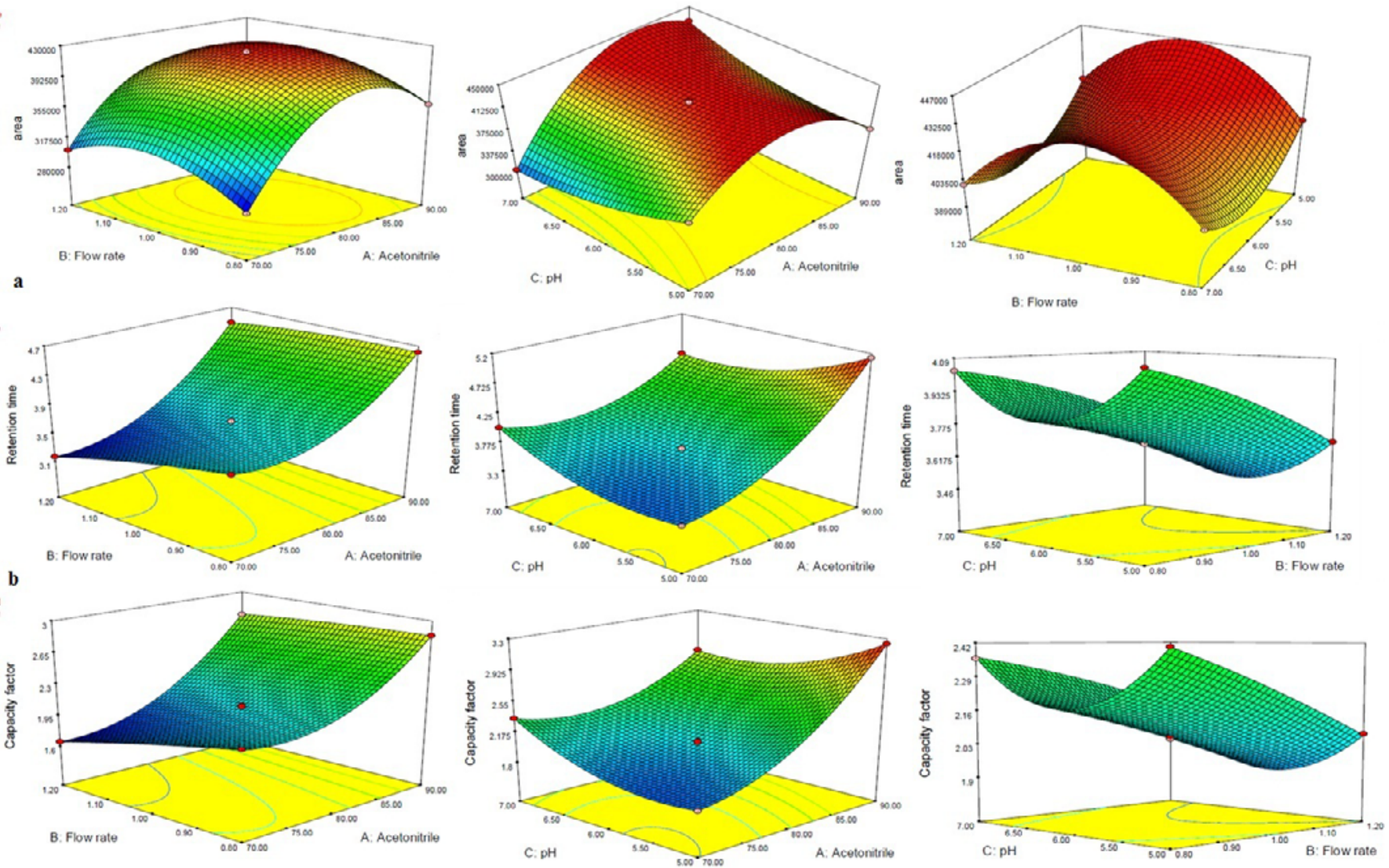

Figure 3: 3D- response surface plot of different independent variables on difference responses (a) area (b) retention time (c) capacity factor.

models and result revealed that best fitted model was quadratic for Y1 (area), Y2 (retention time), and Y3 (capacity factor). Their values of R2, adjusted R2, predicted R2, SD and \% CV are given in Table 2. Finally, the model was observed for ANOVA $(\mathrm{p}<0.001)$, which revealed that the model terms for main effects and interaction effects were statistically significant (Table 3).

It was observed that, combination effect showed that factors $\mathrm{AB}$ and $\mathrm{BC}$ showed antagonistic effect on area, whereas $\mathrm{BC}$ showed synergistic effect (Eq 1). The factor $\mathrm{AB}, \mathrm{BC}$ and $\mathrm{AC}$ had a positive effect on retention time (Eq 2). The combination of factors AB; AC had positive effect, whereas $\mathrm{BC}$ showed negative effect on capacity factor (Eq 3). Three dimensional surface responses were plotted to define the effect of variations on optimization which allowed predicting the behaviour of analyte with the ease and precision. Figure 3 (a-c) depicts the $3 \mathrm{D}$-response surfaces for various response variables. Figure $3 \mathrm{a}$ depicts a dome-shaped response surface plot, characterizing initial increase in the area with increasing the concentration acetonitrile and flow rate, followed by a gradual decrease. Hence, it can be revealed that at the intermediate levels of acetonitrile and flow rate, area was found 

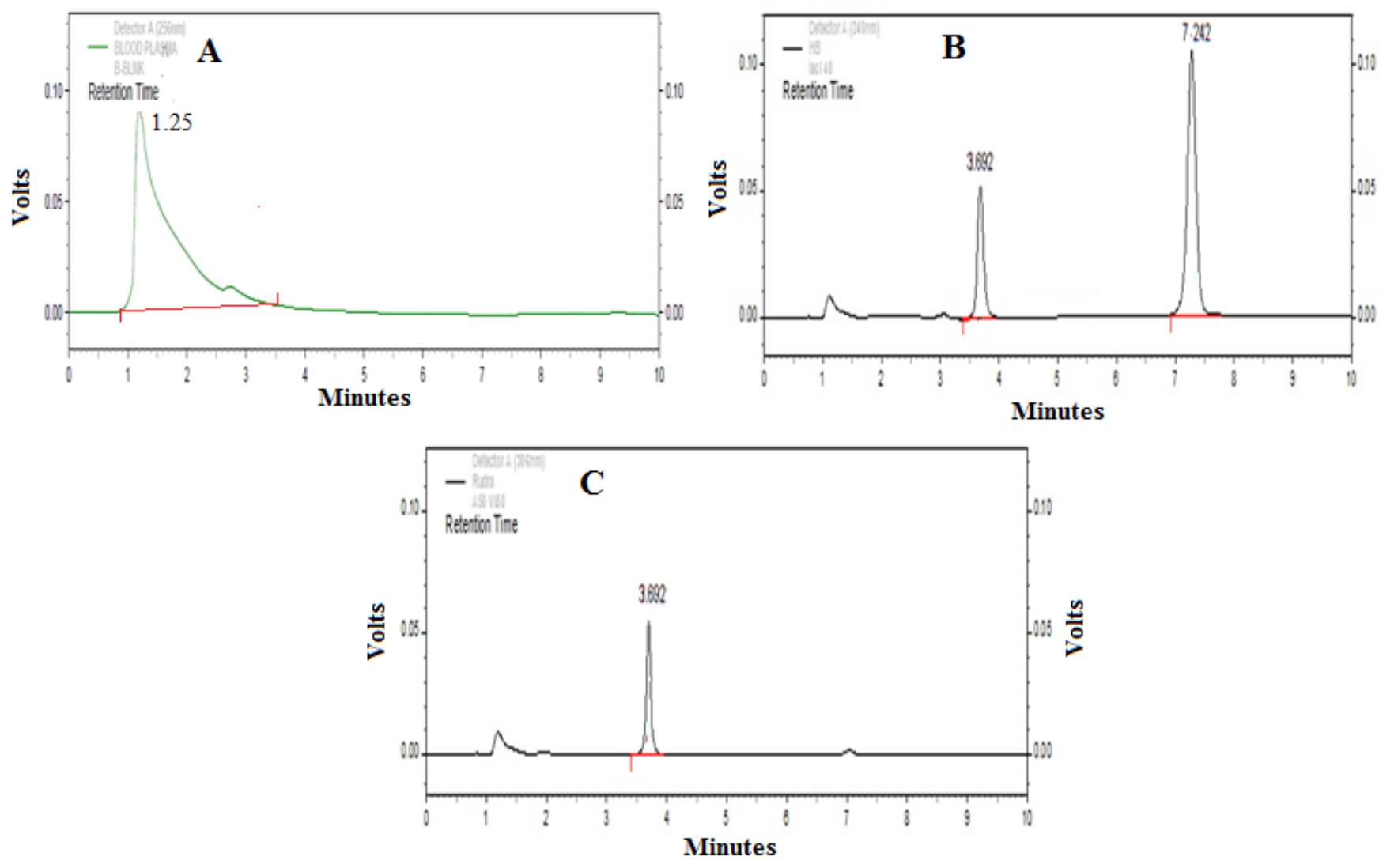

Figure 4: Typical HPLC chromatograms (A) spiked blank plasma (B) spiked lacidipine \& IS (D) spiked lacidipine.

to be maximum. Similarly, Figure $3 \mathrm{~b}$ depicts a relationship between acetonitrile, flow rate and $\mathrm{pH}$ on retention time. It was observed that with increase in acetonitrile concentration there is increase in retention time, whereas with increase in flow rate of mobile phase there is decrease in retention time of LAC. The $\mathrm{pH}$ of mobile phase does not have any significant effect on retention time. Figure $3 c$ portrays an interaction effect and relationship between acetonitrile and flow rate on the capacity factor as the response variable. A curvilinear plot was observed, where with increasing the amount of acetonitrile, a linear increase in the capacity factor was observed and increase in flow rate lead to decrease in capacity factor. Finally, the optimized mobile phase condition was selected by numerical optimization method from the Design-Expert 8.0.7.1 having the desirability value as 1 . The composition of the optimized condition was found to be acetonitrile (85\%), flow rate $(0.95 \mathrm{~mL} / \mathrm{min})$, and $\mathrm{pH}(6)$, with retention time $(4.78$ $\mathrm{min})$, area (423369) and capacity factor (2.82) respectively.

\section{Method validation}

The validation of the method for LAC was performed in accordance with the requirements for new methods that include linearity, sensitivity, selectivity, accuracy, precision, robustness, recovery, matrix effect and stability.

\section{Linearity}

The linearity response for the LAC was evaluated by injecting a total of working standard solutions in range of $20-1200 \mathrm{ng} / \mathrm{mL}$. The correlation coefficient for the calibration regression line was ( $\mathrm{r} 2)$ of 0.9992 whereas the equation of calibration curve was $\mathrm{y}=(0.012 \pm$
$0.0002) \mathrm{x}-0.591 \pm 0.004$ where, $\mathrm{x}$ is the concentration of lacidipine in rat plasma, and $y$ is the peak area ratio of lacidipine with IS. Relative standard deviations for slope and intercept were $1.6 \%$ and $0.67 \%$, respectively.

\section{Selectivity and sensitivity}

The selectivity was evaluated by comparing the spiked plasma samples and blank plasma showed no significant peaks interfering with the quantification of the analyte $(\mathrm{Rt}=3.69)$ and I.S. $(\mathrm{Rt}=7.242)$ (Figure 4). The developed chromatogram of LAC samples showed similar chromatographic behavior to QCs. There is no interference was observed either by matrix or by formulation ingredients, near the retention time, demonstrating method's specificity. The LOD and LOQ were $1.469 \mathrm{ng} / \mathrm{mL}((\mathrm{S} / \mathrm{N} \geq 3)$ and $4.848 \mathrm{ng} / \mathrm{mL}((\mathrm{S} / \mathrm{N} \geq 10)$, respectively, indicating the adequate sensitivity of the method.

\section{Accuracy and precision}

The results obtained for the intra and inter day precision (\%RSD) and accuracy (\%) is summarized in Table 4 . The $\%$ RSD values for intraday and inter-day precision were ranged from $1.87 \%$ and $1.89 \%$ whereas the $\%$ accuracy for the intra-day and inter-day were within $99.00 \%$ and $97.15 \%$, respectively. These ranges show within the acceptable limits as per guidelines.

\section{Extraction recovery and Matrix effect}

The extraction recovery and matrix effect of LAC in rat plasma is given in Table 5. The average extraction recovery were $96.43 \pm$ 
Citation: Qumbar M, Ameeduzzafar, Ali J, Imam SS, Fazil M, et al. (2014) DOE-Based Stability Indicating RP-HPLC Method for Determination of Lacidipine in Niosomal Gel in Rat: Pharmacokinetic Determination. Pharm Anal Acta 5: 314. doi:10.4172/2153-2435.1000314

Page 7 of 11

\begin{tabular}{|c|c|c|c|c|c|c|c|}
\hline \multirow[b]{2}{*}{ Conc. (ng/ml) } & \multirow[b]{2}{*}{ Area } & \multicolumn{3}{|c|}{ Intra day } & \multicolumn{3}{|c|}{ Inter day } \\
\hline & & $\begin{array}{c}\text { Measured conc. } \\
\text { (Mean } \pm \text { SD) }(\mathrm{ng} / \mathrm{mL})\end{array}$ & $\begin{array}{l}\text { Precision } \\
\text { (\% RSD) }\end{array}$ & $\begin{array}{l}\% \text { Accuracy } \\
\text { (Mean } \pm \text { SD) }\end{array}$ & $\begin{array}{c}\text { Measured Conc. } \\
(\text { Mean } \pm \text { SD) }(\mathrm{ng} / \mathrm{mL})\end{array}$ & $\begin{array}{l}\text { Precision } \\
\text { (\% RSD) }\end{array}$ & $\begin{array}{l}\% \text { Accuracy } \\
\text { (Mean } \pm \text { SD) }\end{array}$ \\
\hline 20 (LLQC) & $49254 \pm 978$ & $19.55 \pm 0.32$ & 1.79 & $97.40 \pm 1.80$ & $19.59 \pm 0.33$ & 1.68 & $97.60 \pm 1.55$ \\
\hline 40 (LQC) & $96001 \pm 1073$ & $38.76 \pm 0.67$ & 1.73 & $97.70 \pm 1.30$ & $37.94 \pm 0.71$ & 1.87 & $97.15 \pm 0.85$ \\
\hline 600 (MQC) & $2280111 \pm 1421$ & $575.17 \pm 10.8$ & 1.87 & $98.34 \pm 1.70$ & $573.16 \pm 9.96$ & 1.73 & $98.32 \pm 1.52$ \\
\hline 1000 (HQC) & $4282948 \pm 987$ & $961.20 \pm 17.42$ & 1.81 & $99.00 \pm 1.40$ & $970.18 \pm 16.64$ & 1.71 & $98.97 \pm 1.087$ \\
\hline
\end{tabular}

Table 4: Precision and Accuracy of Lacidipine in rat plasma $(n=6)$.

\begin{tabular}{|c|c|c|}
\hline \multirow{2}{*}{ Conc. $(\mathbf{n g} / \mathrm{mL})$} & ( \%) Recovery (Mean \pm SD) & \multicolumn{2}{|c|}{ Matrix effect } \\
\hline $20(\mathrm{LLQC})$ & $96.43 \pm 4.43$ & $96.34 \pm 3.64$ \\
\hline $40(\mathrm{LQC})$ & $97.98 \pm 3.76$ & $97.87 \pm 2.87$ \\
\hline $600(\mathrm{MQC})$ & $96.90 \pm 4.21$ & $97.98 \pm 2.65$ \\
\hline $1000(\mathrm{HQC})$ & $98.32 \pm 2.76$ & $98.54 \pm 2.36$ \\
\hline
\end{tabular}

Table 5: Extraction recovery, matrix effect $(n=6)$.

\begin{tabular}{|c|c|c|c|}
\hline Condition & LQC (40.00 ng/mL) & MQC (600.00 ng/mL) & HQC (1000.00 ng/mL) \\
\hline \multicolumn{4}{|c|}{ Mobile phase: acetonitrile: $5 \mathrm{mM}$ ammonium acetate buffer } \\
\hline Negative level $(90.1: 9.9, \mathrm{v} / \mathrm{v})$ & $39.90 \pm 1.39(3.48 \%)$ & $595.43 \pm 10.26(1.72 \%)$ & $988.54 \pm 14.64(1.49 \%)$ \\
\hline Zero level $(90: 10, \mathrm{v} / \mathrm{v})$ & $39.93 \pm 1.29(3.23 \%)$ & $597.25 \pm 14.82(2.48 \%)$ & $996.82 \pm 17.35(1.74 \%)$ \\
\hline Positive level (89:10.1, v/v) & $39.91 \pm 1.08(2.71 \%)$ & $593.65 \pm 12.41(2.09 \%)$ & $995.94 \pm 14.76(1.48 \%)$ \\
\hline \multicolumn{4}{|c|}{ Flow rate } \\
\hline Negative level (0.99 mL/min) & $39.88 \pm 1.09(2.73 \%)$ & $596.67 \pm 12.57(2.10 \%)$ & $985.87 \pm 12.34(1.57 \%)$ \\
\hline Zero level (1.0 mL/min) & $39.92 \pm 1.24(3.10 \%)$ & $597.76 \pm 13.89(2.32 \%)$ & $994.26 \pm 10.46(1.31 \%)$ \\
\hline Positive level (1.01 mL/min) & $39.89 \pm 1.15(2.88 \%)$ & $592.39 \pm 15.98(2.69 \%)$ & $998.71 \pm 15.21(1.90 \%)$ \\
\hline
\end{tabular}

Table 6: Robustness of the method $(n=6)$.

\begin{tabular}{|c|c|c|c|c|}
\hline Conc. (ng/ml) & Stability condition & Conc. $(\mathrm{ng} / \mathrm{ml})($ Mean $\pm \mathrm{SD})$ & $\%$ Drug Remaining & $\%$ RSD \\
\hline \multirow{5}{*}{$\begin{array}{c}\mathrm{LQC} \\
(20 \mathrm{ng} / \mathrm{mL})\end{array}$} & Initial $(0 \mathrm{~h})$ & $19.71 \pm 0.31$ & 100 & 1.57 \\
\hline & Short-term stability $\left(25^{\circ} \mathrm{C}, 24 \mathrm{~h}\right)$ & $19.64 \pm 0.34$ & 99.64 & 1.73 \\
\hline & Long-term stability $\left(-80^{\circ} \mathrm{C}, 30\right.$ days $)$ & $19.58 \pm 0.27$ & 99.34 & 1.37 \\
\hline & Three cycles freeze-thaw stability (three cycles, $-20^{\circ} \mathrm{C}$ to $25^{\circ} \mathrm{C}$ ) & $19.50 \pm 0.29$ & 98.93 & 1.48 \\
\hline & Post-preparative stability $\left(10^{\circ} \mathrm{C}, 24 \mathrm{~h}\right)$ & $19.46 \pm 0.28$ & 98.73 & 1.43 \\
\hline \multirow{5}{*}{$\begin{array}{c}\text { HQC } \\
(1000 \mathrm{ng} / \mathrm{mL})\end{array}$} & Initial $(0 \mathrm{~h})$ & $992.76 \pm 16.58$ & 100 & 1.67 \\
\hline & Short-term stability $\left(25^{\circ} \mathrm{C}, 24 \mathrm{~h}\right)$ & $984.89 \pm 15.92$ & 99.20 & 1.61 \\
\hline & Long-term stability $\left(-80^{\circ} \mathrm{C}, 30\right.$ days) & $978.56 \pm 16.23$ & 98.56 & 1.65 \\
\hline & $\begin{array}{l}\text { Three cycles freeze-thaw stability } \\
\text { (three cycles, }-20^{\circ} \mathrm{C} \text { to } 25^{\circ} \mathrm{C} \text { ) }\end{array}$ & $970.45 \pm 16.04$ & 97.75 & 1.65 \\
\hline & Post-preparative stability $\left(10^{\circ} \mathrm{C}, 24 \mathrm{~h}\right)$ & $966.51 \pm 15.94$ & 97.35 & 1.64 \\
\hline
\end{tabular}

Table 7: Summary of ex vivo stability assessment $(n=6)$.

\begin{tabular}{|c|c|c|}
\hline Stress condition & Degradation peak (Rt) & \% drug degradation \\
\hline Acid degradation & $2.158,2.883,4.351$ & 70.44 \\
\hline Base degradation & $2,408,3.44$ & 100 \\
\hline $\mathrm{H}_{2} \mathrm{O}_{2}$ degradation & 4.233 & 86.483 \\
\hline UV light & -- & -- \\
\hline Sun light & -- & -- \\
\hline
\end{tabular}

Table 8: Summary of stress degradation.

\begin{tabular}{|c|c|c|}
\hline $\begin{array}{c}\text { Pharmacokinetic } \\
\text { parameters }\end{array}$ & $\begin{array}{c}\text { Lacidipine oral } \\
\text { suspension }\end{array}$ & $\begin{array}{c}\text { Lacidipine transdermal } \\
\text { niosomal gel }\end{array}$ \\
\hline AUC $_{0-\mathrm{t}}(\mathrm{ng} . \mathrm{h} . / \mathrm{mL})$ & $976.45 \pm 126.43$ & $2500.135 \pm 137.87$ \\
\hline $\mathrm{C}_{\max }(\mathrm{ng} / \mathrm{mL})$ & $104.37 \pm 37.95$ & $131.45 \pm 22.87$ \\
\hline $\mathrm{T}_{\text {max }}(\mathrm{h})$ & $4.00 \pm 0.12$ & $8.00 \pm 0.17$ \\
\hline Half life $(\mathrm{h})$ & $7.2285 \pm 0.16$ & $24.18448 \pm 0.23$ \\
\hline Elimination rate constant & 0.114739 & 0.060862 \\
\hline AUC $_{\text {0-inf }}$ (ng.h./mL) & $1051.059 \pm 123.34$ & $2693.358 \pm 130.25$ \\
\hline AUMC $_{\text {0-t }}$ (ng.h./mL) & $7612.35 \pm 121.65$ & $39524.4 \pm 128.97$ \\
\hline AUMC $_{0 \text {-inf }}$ (ng.h./mL) & $10053.06 \pm 118.87$ & $51973.86 \pm 132.98$ \\
\hline
\end{tabular}

Table 9: Pharmacokinetic parameter of lacidipine oral suspension and transdermal niosomal gel, values represented are mean $\pm S D(n=6)$.
$4.4397 .98 \pm 3.7696 .90 \pm 4.21 \& 98.32 \pm 2.76$ for the low $20 \mathrm{ng} / \mathrm{mL}$ (LLQC), $40 \mathrm{ng} / \mathrm{mL}$ (LQC), 600ng/mL (MQC), and $1000 \mathrm{ng} / \mathrm{mL}$ (HQC) of QC samples respectively. The extraction recovery was found to be efficient and consistent. The matrix effect was measured by comparing peak areas of LAC after spiking evaporated plasma samples with neat standard solutions at four concentration levels ranged from 96.34 to $98.54 \%$ and suggesting that there was no measurable matrix effect interfered with LAC determination in rat plasma samples.

\section{Robustness of the method}

Robustness of the method was done to check the variation in the peak area after small variation in the analytical parameters. It was done on slight change in mobile phase ratio, flow rate and column temperature and results were calculated as \% RSD as shown in Table 6. The low values of $\%$ RSD indicated robustness of the method.

\section{Stability assessment}

The stability in plasma sample was investigated at two QC levels (in LLQC and HQC). The recovery of the analytes relative to that at 
Citation: Qumbar M, Ameeduzzafar, Ali J, Imam SS, Fazil M, et al. (2014) DOE-Based Stability Indicating RP-HPLC Method for Determination of Lacidipine in Niosomal Gel in Rat: Pharmacokinetic Determination. Pharm Anal Acta 5: 314. doi:10.4172/2153-2435.1000314
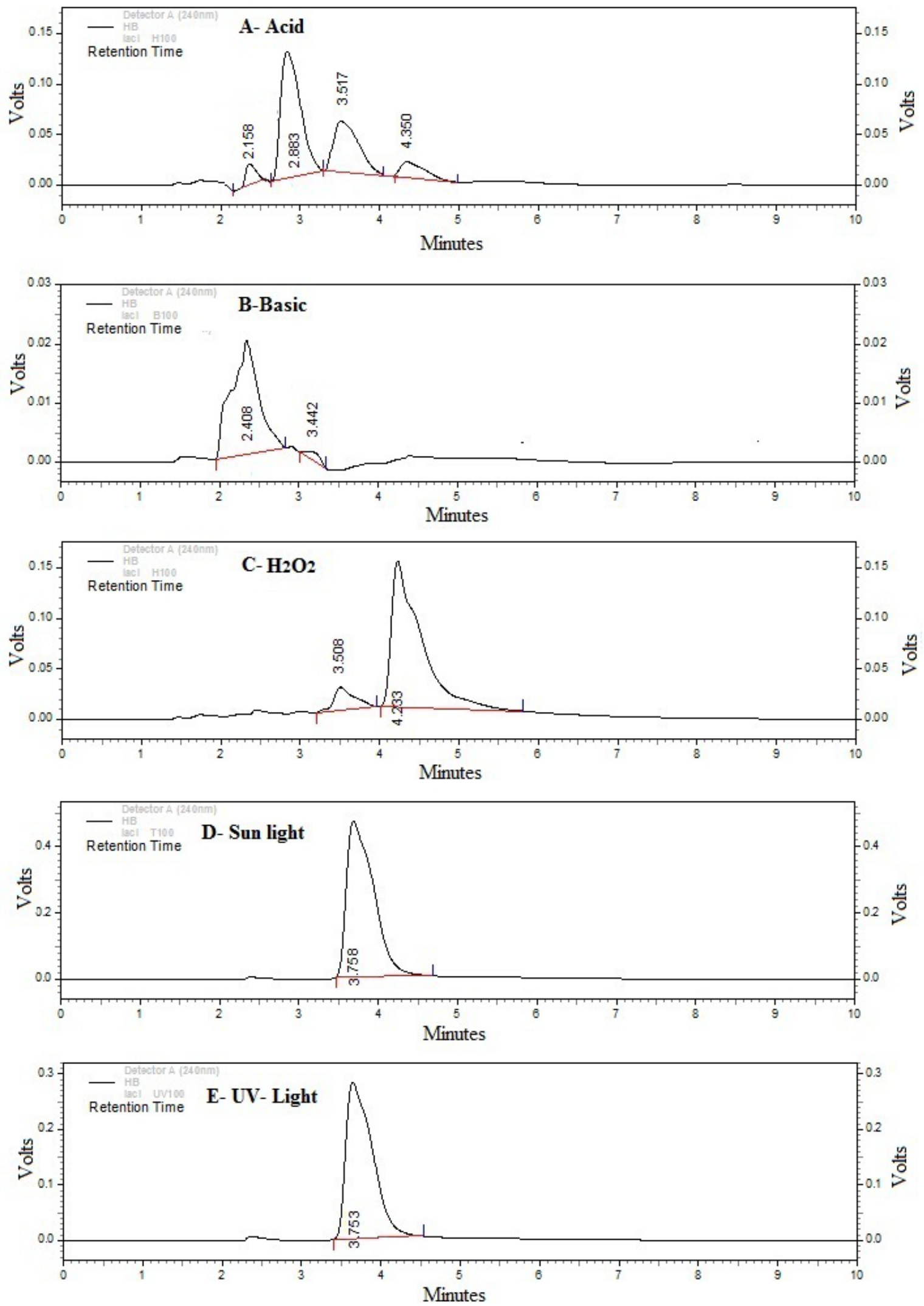

Figure 5: Typical HPLC chromatograms of lacidipine in various stress conditions (A) acid (B) basic (C) $\mathrm{H}_{2} \mathrm{O}_{2}$ oxidation (D) sun light (E) UV- light. 


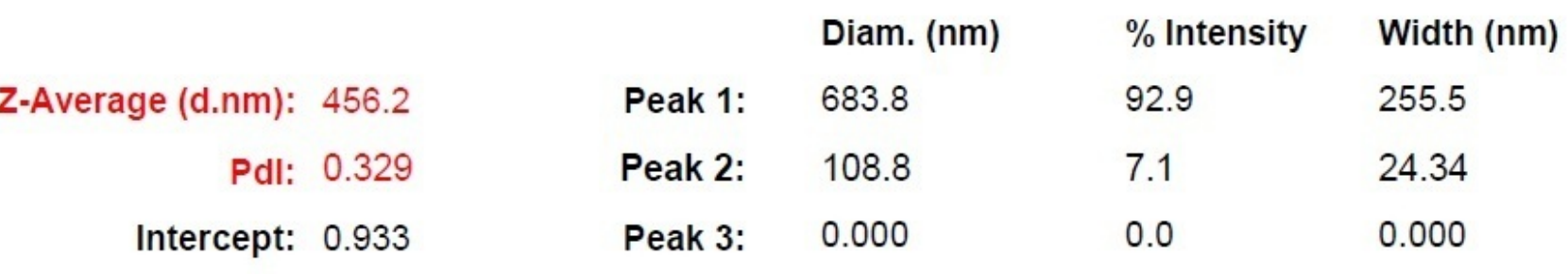

Result quality : Refer to quality report

Size Distribution by Intensity
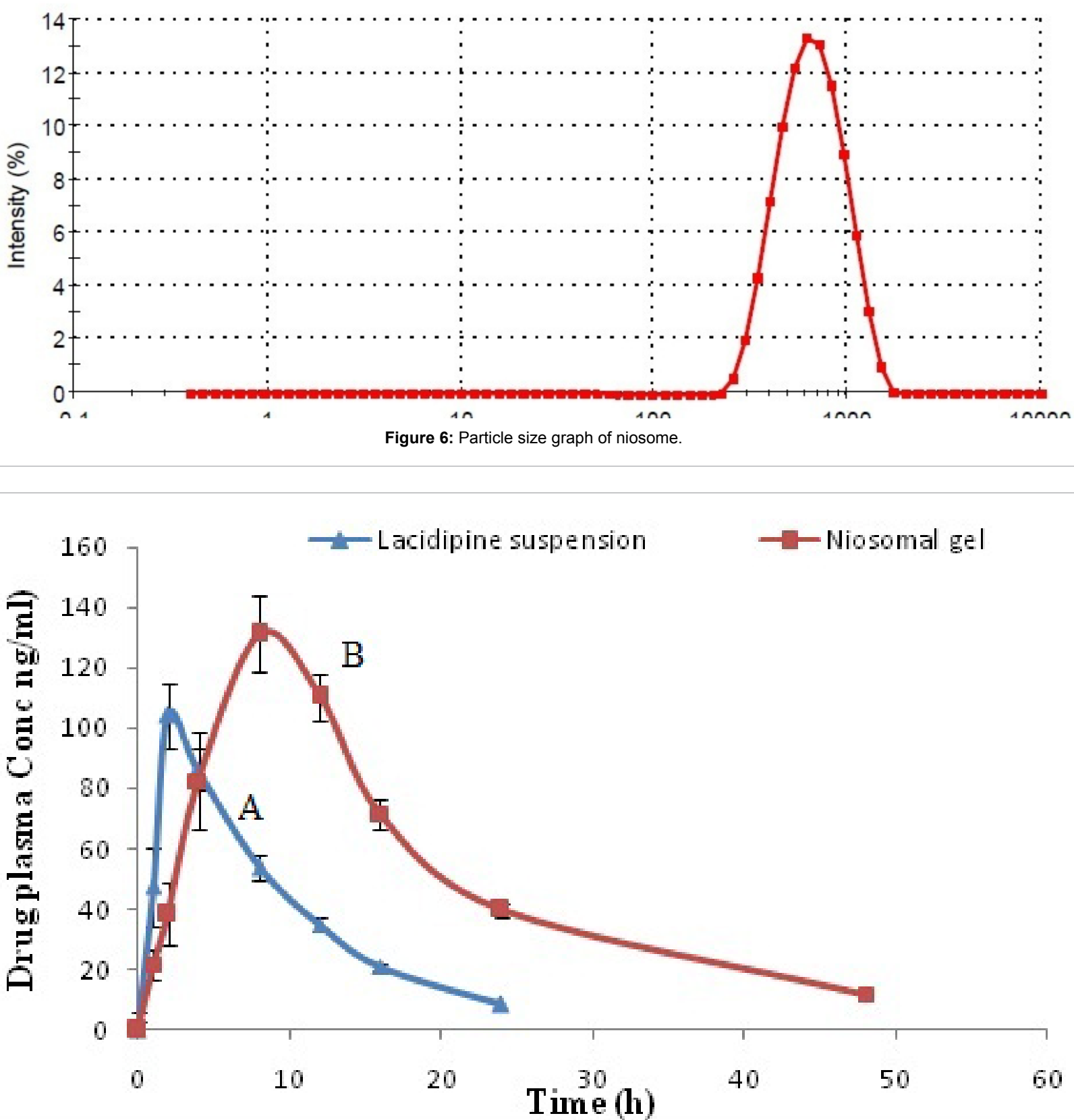

Figure 7: Pharmacokinetic profile of $(A)$ oral suspension of lacidipine $(B)$ transdermal niosomal gel of lacidipine. 
Citation: Qumbar M, Ameeduzzafar, Ali J, Imam SS, Fazil M, et al. (2014) DOE-Based Stability Indicating RP-HPLC Method for Determination of Lacidipine in Niosomal Gel in Rat: Pharmacokinetic Determination. Pharm Anal Acta 5: 314. doi:10.4172/2153-2435.1000314

time zero is reviewed. After 1 month of storage (Long-term stability) the recovery of lacidipine was $99.34 \%$ (LQC), and $98.56 \%$ (HQC). The average value of freeze thaw stability after 1,2 and 3 cycles for lacidipine were recovered as $98.93 \%$ (LQC) and $97.75 \%$ (HQC). After $24 \mathrm{~h}$ (bench-top stability) the recovery of lacidipine was $99.64 \%$ (LQC), and 99.20\% (HQC). The recovery (post processing stability) of lacidipine was $98.73 \%$ (LQC) and $97.35 \%$ (HQC), which showed that lacidipine was stable during all storage conditions (long-term, freeze-thaw, benchtop and post processing stability) Table 8 .

\section{Forced degradation studies}

Acid degradation: Acidic hydrolysis was carried out by exposing the drug in $1 \mathrm{~N} \mathrm{HCl}$ at $90^{\circ} \mathrm{C}$ for $6 \mathrm{~h}$. Three additional peaks of degradation product were observed at RT 2.158, 2.883, 4.351 along with the usual drug peak at RT 3.692. The peaks of degraded products were well resolved from the standard drug peak. In mixture of stressed samples showing around $70.44 \%$ of the drug degraded in acid hydrolysis (Table 8 and Figures 5a).

Base degradation: Basic hydrolysis was carried out by exposing the drug in $1 \mathrm{~N} \mathrm{NaOH}$ at $90^{\circ} \mathrm{C}$ for $6 \mathrm{~h}$. Two peaks of degradation product were observed at RT 2.408, 3.44 and no of the usual drug peak at RT 3.692. The peaks of degraded products were well resolved from the standard drug peak. In mixture of stressed samples showing around $100 \%$ of the drug degraded in acid hydrolysis (Table 8 and Figures $5 b$ ).

Oxidative degradation: The sample degraded with $30 \% \mathrm{v} / \mathrm{v}$ hydrogen peroxide showed additional peaks at different Rt values at RT 4.233 (Table 8 and Figure 5c) no of the usual drug peak at RT 3.692. The samples showing $86.487 \%$ degradation. The peaks of degraded products were well resolved from the standard drug peak.

Photochemical degradation product: The photo degraded sample showed no additional peak when drug solution was left in UV light and sunlight for $48 \mathrm{~h}$ (Table 8 and Figure $5 \mathrm{~d}$ and e). No degradation products were obtained in sunlight and UV- light. It indicated that the LAC is stable in sun light and UV-light i.e., photostable.

Characterization of niosome and gel: The size (Figure 6), PDI, and entrapment efficiency of optimised niosomal formulation were $456.2 \pm$ $4.7 \mathrm{~nm}, 0.329 \pm 0.005$ and $87.34 \pm 1.54 \%$ respectively. The morphology of niosomes was spherical in shape (Figure 6). The viscosity and flux of optimized niosomal gel formulation was found to be $28.34 \mathrm{PaS}$ and $38.43 \mu \mathrm{g} / \mathrm{cm}^{2} / \mathrm{hr}$ which were higher than control transdermal formulation.

Pharmacokinetic study: The results from comparative pharmacokinetic study of oral vs. transdermal niosomal gel (Table 9, Figure 7) revealed that prolonged release was achieved by transdermal route, as compared to the oral suspension $(\mathrm{p}<0.05)$. The $\mathrm{C}_{\max }, \mathrm{T}_{\max }$, AUC0-t of lacidipine were found to be $104.37 \pm 37.95 \mathrm{ng} / \mathrm{mL}, 4.00 \pm$ $0.12 \mathrm{~h}, 976.45 \pm 126.43 \mathrm{ng} / \mathrm{mL} . \mathrm{h}$ after oral suspension administration whereas $131.45 \pm 22.87 \mathrm{ng} / \mathrm{mL}, 8.00 \pm 0.17 \mathrm{~h}, 2500.135 \pm 137.87 \mathrm{ng} / \mathrm{mL} . \mathrm{h}$ respectively after topical niosomal gel $(\mathrm{p}<0.05)$. The $\mathrm{C}_{\max }$, and AUC profiles were compared and found to be higher for transdermal route and the oral route. The $\mathrm{T}_{\max }$ values in all rats were higher for transdermal administration than the oral administration and the difference was statistically significant $(\mathrm{p}<0.05)$. This difference was because of stratum corneum that could delay the permeation of LAC from niosomal gel, whereas, suspension administered by oral route is an immediate release dosage form. The overall mean value of $\mathrm{AUC} 0-\mathrm{t}$ by transdermal delivery was 2.56 times higher than oral route, and the difference was found to be statistically significant $(\mathrm{p}<0.05)$ demonstrating improved bioavailability of LAC from niosomal gel. In the present study the bioavailability of LAC by transdermal route was found to be $25.7 \%$. Therefore for the effective management of chronic hypertension LAC in the form of niosomal gel could provide an effective treatment.

\section{Conclusion}

The present research work describes the development, optimization by design of experiment, validation and application of a RP-HPLC method for the quantitative analysis of LAC in rat plasma. LAC is extracted from the plasma by a simple and fast liquid-liquid extraction method. This result of method is satisfactory in terms of selectivity, accuracy, precision, sensitivity, matrix effects and reproducibility. The degradation study results shows that the drug is photo stable. It has been successfully applied in pre-clinical pharmacokinetic research and will be used in future clinical pharmacokinetic studies.

\section{Acknowledgement}

The authors are thankful to Government of India, All India Council for Technical Education. New Delhi, India for the granting GPAT scholarship which supported this study.

\section{References}

1. Geng Y, Zhao L, Zhao J, Guo B, Ma P et al. (2014) Development of a supercritical fluid chromatography-tandem mass spectrometry method for the determination of lacidipine in beagle dog plasma and its application to a bioavailability study. J Chromatogr B Analyt Technol Biomed Life Sci 945-946: 121-6.

2. Chatki PK, Hotha KK, Kolagatla PR, Bharathi DV, Venkateswarulu V (2013) LC-MS/MS determination and pharmacokinetic study of lacidipine in human plasma. Biomed Chromatogr 27: 838-845.

3. Basalious EB, Shawky N, Badr-Eldin SM (2010) SNEDDS containing bioenhancers for improvement of dissolution and oral absorption of lacidipine. I: development and optimization. Int J Pharm 391: 203-211.

4. McCormack PL, Wagstaff AJ (2003) Lacidipine: a review of its use in the management of hypertension. Drugs 63: 2327-2356.

5. Tang J, Zhu R, Zhao R, Cheng G, Peng W (2008) Ultra-performance liquid chromatography-tandem mass spectrometry for the determination of lacidipine in human plasma and its application in a pharmacokinetic study. J Pharm Biomed Anal 47: 923-928.

6. Nagaraju PT, Channabasavaraj KP, Shantha Kumar PT (2011) Development and Validation of Spectrophotometric Method for estimation of Lacidipine in Tablet Dosage Form. Int J PharmTech Res 3: 18-23

7. Nozal MJ, Bernal JL, Jiménez JJ, Martín MT, Diez FJ (2004) Development and validation of a liquid chromatographic method for determination of lacidipine residues on surfaces in the manufacture of pharmaceuticals. J Chromatogr A 1024: $115-122$

8. Vinodh M, Vinayak M, Rahul K, Pankaj P (2012) Development and validation of a HPLC method for the determination of lacidipine in pure form and in pharmaceutical dosage form, J Anal Sci 16: 213-219.

9. Muralidharan S (2013) High Performance Liquid Chromatographic Method Development and its Validation for Lacidipine. Int J PharmTech Res 5: 79-85.

10. Beg S, Hasnain MS, Swain S, Kohli K (2001) Validated stability-indicating LC method for estimation of Amoxicillin Trihydratein pharmaceutical dosage forms and time dependant release formulations. Int J Pharm Sci Nanotech 4: 14231427

11. Hasnain MS, Rao S, Singh MK, Vig N, Gupta A, et al. (2013) Development and validation of LC-MS/MS method for the quantitation of lenalidomide in human plasma using Box-Behnken experimental design. Analyst 138: 1581-1588.

12. Srinubabu G, Raju ChA, Sarath N, Kumar PK, Rao JV (2007) Developmen and validation of a HPLC method for the determination of voriconazole in pharmaceutical formulation using an experimental design. Talanta 71: 14241429.

13. Imam SS, Aqil M, Akhtar M, Sultana Y, Ali A (2014) Optimization of mobile phase 
Citation: Qumbar M, Ameeduzzafar, Ali J, Imam SS, Fazil M, et al. (2014) DOE-Based Stability Indicating RP-HPLC Method for Determination of Lacidipine in Niosomal Gel in Rat: Pharmacokinetic Determination. Pharm Anal Acta 5: 314. doi:10.4172/2153-2435.1000314

by 32-mixture design for the validation and quantification of risperidone in bulk and pharmaceutical formulations using RP-HPLC. Anal Methods 6: 282-288

14. ZivanoviÄ L, Licanski A, Zecevi M, JociÄ B, KostiÄł M (2008) Application of experimental design in optimization of solid phase extraction of mycophenolic acid and mycophenolic acid glucuronide from human urine and plasma and SPE-RP-HPLC method validation. J Pharm Biomed Anal 47: 575-585.

15. Iriarte G, Ferreiros N, Ibarrondo I, Alonso RM, Maguregi MI, et al. (2006) Optimization via experimental design of an SPE-HPLC-UV-fluorescence method for the determination of valsartan and its metabolite in human plasma samples. J Sep Sci 29: 2265-2283.

16. Medenica M, Jancic B, Ivanovic D, Malenovic A (2004) Experimental design in reversed-phase high-performance liquid chromatographic analysis of imatinib mesylate and its impurity. J Chromatogr A 1031: 243-248.

17. Lin K (1999) Discussion on papers by Box and Liu, Box, and Myers. J Quality Technol 31: 61-66.

18. Hockman KK, Berengut D (1996) Design of experiments. Chem Eng 102:142148.

19. Fabre H (1996) Robustness testing in liquid chromatography and capillary electrophoresis. J Pharm Biomed Anal 14: 1125-1132.
20. Lewis GA, Mathieu D, Phan-Tan-Luu R (1999) Pharmaceutical Experimental Design, Marcel Dekker, New York.

21. Pani NR, Nath LK, Singh AV, Mahapatra SK (2012) Development and validation of analytical method for the estimation of nateglinide in rabbit plasma. J Pharm Anal 2: 492-498.

22. Hubert P, Chiap P, Crommen J, Boulanger B, Chapuzet E, et al. (1999) The SFSTP guide on the validation of chromatographic methods for drug bioanalysis Washington conference to the laboratory. Analytica Chimica Acta 391: 135-148.

23. Dams R, Huestis MA, Lambert WE, Murphy CM (2003) Matrix effect in bioanalysis of illicit drugs with LC-MS/MS: influence of ionization type, sample preparation, and biofluid. J Am Society for Mass Spectrometry 14: 1290-1294.

24. Food and Drug Administration, HHS (2003) International Conference on Harmonisation; Stability Data Package for Registration Applications in Climatic Zones III and IV; Stability Testing of New Drug Substances and Products; availability. Notice. Fed Regist 68: 65717-65718.

25. Imam SS, Aqil M, Akhtar M, Sultana Y, Ali A (2014) Formulation by designbased proniosome for accentuated transdermal delivery of risperidone: in vitro characterization and in vivo pharmacokinetic study. Drug Deliv. 